\title{
Indígenas na Universidade: uma comunidade criativa de práticas em Design colaborativo
}

\section{Indigenous people at University: a creative community of collaborative Design practice}

\author{
Ana Luisa Boavista Lustosa Cavalcante, Universidade Estadual de Londrina. \\ anaboavista@uel.br
}

Natalia Maria Devergenes, Universidade Estadual de Londrina.

ndevergenes@gmail.com

\section{Resumo}

A colaboração é um aspecto essencial da atividade contemporânea do Design, pois atende às necessidades da Nova Economia que direciona a reconfigurações estruturais nos modos de vida, produção e consumo. Comunidades criativas são casos promissores de iniciativas locais que provocam descontinuidades sistêmicas rumo à sustentabilidade. Este artigo objetiva contextualizar duas oficinas de Design entre indígenas e não-indígenas da Universidade Estadual de Londrina a partir dos conceitos de Comunidades Criativas e Comunidades de Prática. Para tanto, foi realizada uma sistematização dos referenciais teóricos e dos registros etnográficos das oficinas em mapas mentais para comparação conceitual. A pesquisa é de natureza exploratória e descritiva, pautada na metodologia qualitativa da pesquisa social. Os resultados mostram que há uma relação entre as Comunidades Criativas e de Prática no contexto da Sustentabilidade Sociocultural; e que as oficinas realizadas são casos promissores de inovação no processo de Design.

Palavras-chave: Design Colaborativo, Comunidades Criativas, Comunidades de Prática, Estudantes indígenas.

\begin{abstract}
Collaboration is an essential aspect in contemporary Design activity, as it meets the needs of the New Economy which leads society to structural reconfigurations in way of living, production and consumption. Creative communities are promising cases to systemic discontinuities towards sustainability. This paper aims to contextualize two Design workshops between indigenous and non-indigenous students of Londrina State University. For this, a systematization of theorical references and ethnographic registers were performed in mind maps. The nature of the research is exploratory and descriptive, based on qualitative methodology of social research. The results show there is a relationship between Creative Communities and Communities of Practice in the context of Socio-cultural Sustainability; and the Design workshops are potential cases of innovation in Design Process.
\end{abstract}

Keywords: Collaborative Design, Creative Communities, Communities of Practice, Indigenous Students 


\section{Introdução}

A colaboração no processo de Design é um fenômeno historicamente recente. Novas formas de trabalhar são desenvolvidas por atuantes na área, o que traz novas possibilidades para a nossa sociedade em prol da sua sustentabilidade (MARTTILA, 2018).

O design colaborativo é tratado por Manzini (2010, p. XIII) como um aspecto essencial no contexto contemporâneo, pois ele tem a capacidade de trabalhar com as necessidades da chamada "Nova economia", que tira a centralidade do consumo de produtos. Ela exige processos e soluções projetuais de Design que são sustentáveis em todos os âmbitos: ambiental, cultural, social, político e econômico.

Manzini (2008) em 'Design para a Inovação Social e Sustentabilidade' trata do conceito de Comunidades Criativas como grupos locais que trazem inovações e soluções criativas para problemas enfrentados. Outro conceito que pode ser comparado ao de Comunidades Criativas é Comunidades de Prática (CoPs), trabalhado por Wenger (1998) em Communities of Practice: learning, meaning and Identity. Tais conceitos serão tratados neste artigo como fortemente relacionados ao processo de Design Colaborativo.

O fenômeno da Globalização fortaleceu uma relação de dominação econômica, política, social e cultural entre os países de Centro e Periferia (BONSIEPE, 2011). Daremos enfoque no aspecto social dessa dominação, pois com a formação histórico-cultural do Brasil as identidades nativas indígenas perderam sua visibilidade e até hoje apresentam dificuldades de integração à sociedade brasileira:

Um reflexo local dessa dominação é a realidade dos estudantes indígenas da Universidade Estadual de Londrina, situada no Paraná. As dificuldades de integração estão relacionadas tanto a condições de permanência, tais como acesso à moradia, materiais didáticos e bolsas de auxílio, quanto a condições de adaptação cultural e educacional e visibilidade (CAVALCANTE et al., 2018). Muitos estudantes indígenas que conseguem entrar na Universidade desistem ou reprovam muitas vezes porque não conseguem conciliar seus hábitos culturais com os hábitos que a Universidade exige.

A necessidade é, portanto, de encontrar meios dentro da Universidade que estimulem visibilidade cultural para esses estudantes no meio universitário, o que pode abrir novas possibilidades e alternativas de articulação das condições de permanência para a integração dessas comunidades no nível local.

Em busca de suprir essa demanda, o Projeto de Pesquisa intitulado Design para a Sustentabilidade Sociocultural tem realizado oficinas colaborativas (CAVALCANTE et al., 2018) com os estudantes indígenas, que são articulados por meio da Comissão Universidade para os Índios (CUIA) para ensinar aos estudantes não-indígenas sobre a cultura visual em forma de grafismos das comunidades indígenas presentes na Universidade.

Nessas oficinas, foram trabalhadas aplicações desses grafismos em produtos de design gráfico e design de moda: camisetas, lenços, estojos, entre outros. Isso gerou um interesse por parte dos estudantes indígenas de formar um que produz grafismos para serem aplicados nesses produtos. 
Assim, as questões que norteiam esta pesquisa são: Esse fenômeno das oficinas envolvendo estudantes indígenas e não-indígenas pode vir a ser a formação de uma Comunidade de Prática ou Comunidade Criativa? Qual a relação teórica entre os conceitos Comunidades Criativas e Comunidades de Prática (CoPs)?

O objetivo geral deste artigo é contextualizar as oficinas a partir de dois conceitos teoricamente relacionados: Comunidades criativas (MANZINI, 2008) e Comunidades de Prática (WENGER, 1998). Especificamente, sistematizar os aspectos que caracterizam uma Comunidade de Prática segundo Wenger (1998); sistematizar os aspectos sociais presentes na dinâmica das pessoas participantes das oficinas, constituído por estudantes indígenas e não-indígenas dentro e fora da UEL; e relacionar tais aspectos com o conceito de Comunidades de Prática de Wenger (1998) e de Comunidades Criativas de Manzini (2008).

Este artigo trabalha o recorte social da sustentabilidade, em busca de suprir uma escassez de publicações sobre Sustentabilidade social na academia do Design. É de caráter teórico e crítico em relação à prática do Design.

\section{Metodologia}

Esta pesquisa tem seu tratamento baseado na metodologia da pesquisa social (MINAYO, 1994) e qualitativa (REY, 2015). Considera-se que a realidade do objeto de estudo, composto por grupos sociais, é regida por significados atribuídos por seus próprios agentes participantes (MINAYO, 1994, p.15; REY, 2015, p. 21).

Logo, o objetivo da pesquisa social qualitativa é compreender os grupos sociais por meio da dinâmica de seus significados, considerando suas individualidades e coletividades (MINAYO, 1994, p.21; REY, p. 5). Para Minayo (1994, p.19), utilizar de um aporte teórico para a compreensão desses significados é uma forma de estruturar e sistematizar o pensamento, guiando futuras reflexões e ações. Nesse sentido, a legitimidade do conhecimento produzido por uma pesquisa social qualitativa está

[...] na sua continuidade e na sua capacidade de gerar novas zonas de inteligibilidade acerca do que é estudado e de articular essas zonas em modelos cada vez mais úteis para a produção de novos conhecimentos" (REY, 2015, p. 6).

O levantamento de dados teóricos para sistematização foi realizado por revisão bibliográfica assistemática e documental. Para tratamento do conceito de Comunidades de Prática, trabalhado por Wenger (1998), foi feita uma revisão bibliográfica de Communities of Practice e um mapa mental (SAMPAIO, 2017) na plataforma online 'Coggle' para sistematização dos dados.

A sistematização do funcionamento dos grupos das oficinas foi feita pela estratégia etnográfica (MARTINS; THEÓPHILO, 2016; URIARTE, 2016), que exige que sejam realizados registros para interpretações qualitativas dos acontecimentos. Eles podem conter intervenções das pesquisadoras, constituindo uma relação dialógica (URIARTE, 2016, p. 5) no fazer etnográfico, uma observação participante. Aqui, um aporte teórico se faz importante, mas os dados registrados podem ou não corresponder à teoria previamente estudada (URIARTE, 2016, p. 2). Encontrar 
essas diferenças entre a teoria e a realidade é o que traz inovação para o conhecimento aqui trabalhado.

Textos, anotações, desenhos e fotografias foram apoio para uma revisão dos acontecimentos e posterior sistematização e organização das características do grupo social num mapa mental (SAMPAIO, 2017), para que fossem comparadas com as teorias das CoPs de Wenger (1998) e das Comunidades Criativas de Manzini (2008).

\section{Referencial teórico}

No contexto da modernidade, que se perdurou até a década de 60 no mundo e até a década de 1980 no Brasil, o Design recebeu predominantemente um tratamento racionalizado por cientistas, arquitetos e engenheiros. Buscou-se sistematizar o processo enigmático de criação de artefatos o processo de Design - para responder às demandas de mercado da sociedade de massa (MARTTILA, 2018, p. 22), dando sentido à famosa máxima "A forma segue a função" (CARDOSO, 2016, p. 18).

Assim, surgiram os vários métodos e processos sistematizados que conhecemos hoje, correspondentes à abordagem que chamamos de Design Thinking voltados diretamente para a solução de problemas sistêmicos (BUCHANAN, 1992). Esse tratamento resultou na inclusão do Design em diversas áreas da academia e de atuação profissional interdisciplinares, sofrendo influências e sendo influenciado por todas elas (MARTTILA, 2018, p. 26).

O tratamento hegemônico do Design pautado nos princípios do capitalismo moderno foi criticado por pensadores como Papanek (1971), Bonsiepe (2015) e Manzini (2008); por não apresentar soluções que considerem os problemas estruturais e sistêmicos presentes no meio ambiente e da sociedade. A mudança do paradigma modernista no Design se inicia com Papanek, que publicou em 1971 o livro Design for the Real World, em que chama a atenção de todos para a falta de responsabilidade social do Design modernista. Depois dessa publicação, surgiram processos e abordagens que consideram problemas mais prioritários, como a fome, a pobreza e a desigualdade social (MARGOLIN, V; MARGOLIN, S, 2002, p. 24).

Entende-se hoje que essa atuação surge como uma alternativa ao Design para o mercado (MARGOLIN, V; MARGOLIN, S, 2002) e se desdobrou ao que hoje conhecemos por Design Social ou Design para a Sustentabilidade. Neste artigo, o termo Design Social não é suficiente para tratar desse segmento, sendo assim preferido a utilização dos termos "Design para a sustentabilidade social".

Dialogando com esse paradigma da realidade socioeconômica pós-moderna, Manzini (2010) aparece no prefácio do livro Metaprojeto: o design do design para falar sobre a Nova Economia:

A próxima economia não é baseada em bens de consumo. A crise mostra que o contínuo crescimento do consumo é insustentável ambiental e economicamente. A próxima economia reorienta essas atividades para algo bastante diferente. Seus "produtos" são entidades complexas, baseadas na interação entre pessoas, produtos e lugares (p. IX). 
Manzini nos alerta que as demandas da contemporaneidade são outras. Não se deve mais projetar para o incentivo do consumo. O foco do projeto não deve ser o produto (MANZINI, 2010 p. XI). Para Manzini, o Design deve ser orientado para "entidades complexas, baseadas na interação entre pessoas, produtos e lugares" (MANZINI, 2010 p. IX).

A Nova economia pede para que nos atentamos à sustentabilidade em todos os âmbitos: ambiental, econômico, social e político. Para isso, precisamos pensar sistemicamente. Assim, o desenvolvimento sustentável não deve ser confundido com "desenvolvimento tecnológico", nem mesmo apenas como se referindo à sustentabilidade ambiental, pois ele é sobre "respeito aos direitos humanos, à igualdade, ao empoderamento e à liberdade" " (MARTTILA, 2018, p. 15, tradução nossa). A adequação do Design a esse novo contexto no âmbito social envolve a colaboração entre designers e outros agentes sociais no processo de criação.

\section{Comunidades criativas}

Manzini (2008) trata dos temas Inovação social e Sustentabilidade na sua relação com o Design de forma crítica e sistêmica. Afirma que o modo de vida atual, baseado na noção de bemestar a partir do consumo incessante, acaba com os recursos naturais do planeta; reconhecendo assim um fator social para as condições ambientais do ecossistema. Dessa forma, Manzini defende que devemos romper com os costumes da atualidade, criando e experimentando novas alternativas de comportamento que alterem a noção de bem-estar, principalmente no que se diz respeito a: consumir menos recursos ambientais; incentivar o uso de bens comuns; aumentar o tempo lento e contemplativo na nossa rotina ${ }^{2}$; e realçar a qualidade dos contextos em que vivemos. Esse rompimento estrutural na sociedade é a "descontinuidade sistêmica" (MANZINI, 2008, p. 25):

A transição rumo à sustentabilidade [...] será um processo de aprendizagem social largamente difuso no qual as mais diversificadas formas de criatividade, conhecimento e capacidades organizacionais deverão ser valorizadas do modo mais aberto e flexível possível. Um papel particular será desempenhado por uma série de iniciativas locais que, por diversos motivos, serão cada vez mais capazes de romper os padrões consolidados e nos guiar rumo a novos comportamentos e modos de pensar. São por este motivo denominadas de descontinuidades locais (MANZINI, 2008, p. 61).

O caráter local é o que difere a Inovação social da Inovação tecnológica ou de Mercado (MANZINI, 2008, p. 62). Inovação social é o modo como os grupos sociais encontram soluções para suas necessidades, envolve rupturas nas estruturas sociais, tem caráter sistêmico e uma dinâmica “de baixo para cima” (MANZINI, 2008, p. 75). Já a Inovação de mercado não promove descontinuidades e tem um funcionamento impositivo e hierárquico.

As iniciativas locais são as mais eficientes para criar e experimentar novos comportamentos sistemicamente. Elas são "Casos promissores" (MANZINI, 2008, p. 64), pois moldam os interesses pessoais considerando as necessidades socioambientais.

\footnotetext{
1 "SD connects ideas of progress into discussions on global human rights, equality, and individual empowerment and freedom to contest the fixed truths on cultural and technological development."

2 Manzini refere-se a momentos da nossa existência em que não estamos encarregados da necessidade de produzir capital.
} 
É a partir da noção de iniciativas locais que surge o conceito de Comunidades Criativas, central para a fundamentação desta pesquisa. Suas principais características são: (1) usam criatividade para quebrar modelos dominantes; (2) geram descontinuidades locais; (3) são um espaço onde cada grupo social trabalha com suas demandas e oportunidades. Quando se tornam uma organização madura, formam um "empreendimento social difuso" (MANZINI, 2008, p. 68), estabelecendo relações de troca de conhecimento e criatividade entre outras comunidades criativas similares (relação entre pares) e também entre instituições, empresas e outras organizações formais (relações de cima para baixo) (MANZINI, 2008, p. 75).

A dinâmica das Comunidades Criativas é baseada em relações informais entre os seus membros. Isso é muito benéfico, pois assim a comunidade produz o prazer de levar a vida em comum e reforça o tecido social, melhorando a qualidade do ambiente e do contexto em que vivem. Esse aspecto tem forte relação com o incentivo ao consumo de bens compartilhados, em oposição aos bens individuais, que são parte do problema atual da economia (MANZINI, 2008, p. 68).

Com ênfase à sua forma de organização, as comunidades criativas são inovadoras pois desafiam a ordem e modos de pensar tradicionais. Dessa forma, as soluções derivadas dessa dinâmica vão espontaneamente contra os interesses do mercado. As comunidades criativas tornam a criatividade e a inovação práticas acessíveis, não limitadas a empresas ou ao conhecimento formal (MANZINI, 2008, p. 70), possibilitando e incentivando uma sociedade baseada no conhecimento, altamente sustentável, que é a necessidade da realidade pós-moderna (MARTILLA, 2018, p. 17).

\section{Comunidades de prática}

O conceito de Comunidades de Prática (CoPs) trabalhado por Wenger (1998) pode ser uma sistematização do que entendemos por Comunidades Criativas. Apesar do caráter semiestruturalista de sua obra, a escrita de Wenger é bem discursiva, o que traz a necessidade de organização das informações que caracterizam as CoPs em mapas mentais (SAMPAIO, 2017).

Wenger inicia a sua produção tratando do incentivo a um aprendizado mais eficiente e humano. Defendendo o caráter social do ato de aprender, As CoPs são o espaço onde esse aprendizado está em sua forma mais potencializada, pois envolve os agentes sociais das comunidades em uma prática cotidiana carregada de reflexões, interações pessoais e criatividade.

Os principais conceitos e características, interdependentes, de uma comunidade de prática são: 1) A Prática; 2) O sentido; 3) A Identidade; e 4) A Comunidade.

\section{A Prática}

Prática é a atividade central dos agentes de um grupo social, bem como o elemento central da construção do conhecimento. Ela é uma atividade consciente (WENGER, 1998, p. 47), que desencadeia envolvimento e interação entre as pessoas, promovendo o surgimento de significados 
e identidades. Wenger afirma que a prática tem caráter dinâmico, sempre com continuidades e descontinuidades, sofrendo alterações ao longo do tempo como consequência da interação entre os agentes sociais (WENGER, 1998, p. 98). Isso demonstra a perspectiva semi-estruturalista do autor, que não vê a prática como algo completamente engessado, mas que também não é completamente líquido e sem padrões.

O sentido

O sentido de uma comunidade de prática é gerado a partir do momento em que há padrões nas práticas (WENGER, 1998, p.52). Envolve os significados que a comunidade produz a partir de negociação (WENGER, 1998, p. 53), caracterizando um processo contínuo de troca entre os atores sociais (WENGER, 1998, p. 54), que acontecem em dois aspectos: a reificação, que é a capacidade de "tornar concreto o abstrato" (WENGER, 1998, p. 58); e a participação, que é o modo como a comunidade interage imaterialmente com os artefatos materiais (WENGER, 1998, p. 67).

\section{A identidade}

É construída na negociação participativa de significados. A identidade de uma CoP é uma construção mutual e intersubjetiva. Por isso, a identidade das CoPs também está associada a relações de poder, o que significa que o contexto político de uma comunidade deve ser considerado.

\section{A comunidade}

A formação de uma comunidade é decorrente das interações entre os agentes sociais em torno de uma prática ao longo do tempo. É no campo da comunidade em que acontecem as interações e negociações, tanto entre os membros da comunidade como os membros de fora e outras comunidades. A participação de cada membro de uma CoP pode ocorrer pelos mecanismos de conexão ou pela prática.

O Encontro de Práticas é o momento em que as CoPs podem compartilhar de seus diversos conhecimentos, modos de pensar e agir com as outras CoPs, que formam uma rede interconectada de conhecimento. Os mecanismos comunicativos incluem: a tradução de termos (WENGER, 1998, p. 199); a produção de artefatos; e a produção de bens culturais.

Tratando sobre a produção desses artefatos de conexão Wenger indica sua noção ampla da definição de Design, que é aberta para a produção de qualquer artefato: "Neste contexto, o design de artefatos - documentos, sistemas, ferramentas - é frequentemente o design de objetos de conexão (WENGER, 1998, p. 108, tradução nossa).

As diferentes formas de conexões entre as Comunidades de Prática formam, ao longo de seu desenvolvimento, redes sociais complexas que articulam práticas e conhecimento criativo. É 
possível observar, como resultado das práticas conexas, uma textura de continuidades e descontinuidades nessa paisagem (WENGER, 1998, p. 119).

Visto isso, As Comunidades de Prática representam a solução teórica que se mostra mais capaz de responder aos problemas sociais estruturais tratados por Manzini (2008). Elas podem corresponder a uma sistematização do conceito de Comunidades Criativas, pois são focos sociais de aprendizado e criatividade, além de ser grupos sociais que abrem espaço para relações informais (WENGER, 1998, p. 119) entre seus membros, considerando os sentimentos e significados humanos envolvidos (WENGER, 1998, p. 134). As CoPs são fontes sustentáveis de energia social.

\section{Soluções habilitantes}

Manzini (2008) defende como viabilização do surgimento de soluções locais sustentáveis a sistematização do incentivo à formação de e fomento às organizações colaborativas, com uma gestão que torna as comunidades criativas mais acessíveis, eficazes, replicáveis e atraentes. A existência de relações interpessoais dinâmicas e profundas entre os membros das comunidades criativas é um fator que afeta muito a viabilidade delas (MANZINI, 2008, p. 88).

\section{Estudantes indígenas na Universidade}

No ano de 2017 o projeto de pesquisa Design Para a Sustentabilidade Sociocultural da UEL organizou dois dias de oficinas colaborativas em que o objetivo principal era tratar de grafismos indígenas, transmitindo um conhecimento ancestral e alimentando a visibilidade das comunidades indígenas dentro da Universidade. Houve, no momento da oficina, uma integração por meio da prática do desenho de grafismos da parte dos estudantes indígenas e não-indígenas, evidenciando o compartilhamento de conhecimentos diversos entre um grupo social e outro. Ela foi divulgada nas redes sociais e na Universidade, buscando um público aberto.

A oficina foi realizada em dois dias, sendo que no primeiro houve uma apresentação ministrada pela coordenadora do projeto de pesquisa sobre os conhecimentos visuais indígenas em geral e apresentações dos estudantes indígenas sobre sua cultura. Depois, os participantes separaram-se em grupos, cada grupo com pelo menos um estudante indígena para falar sobre os grafismos e desenhá-los juntamente com os não-indígenas.

Os estudantes não-indígenas tinham várias origens na Universidade. Havia professores e estudantes não-indígenas do curso de Ciências Sociais, Design, Artes Visuais e diversas outras áreas do conhecimento envolvidas. Nos grupos de desenho e conversas, os não-indígenas faziam perguntas para tirar dúvidas, e os indígenas falavam não só sobre os desenhos, mas sobre os significados que eles têm e como a cultura deles lida com a transfiguração étnica.

No final do primeiro dia, todos os desenhos foram expostos na parede para uma discussão informal sobre eles, ocorrendo inclusive a pintura corporal em algumas pessoas (Figura 1). 

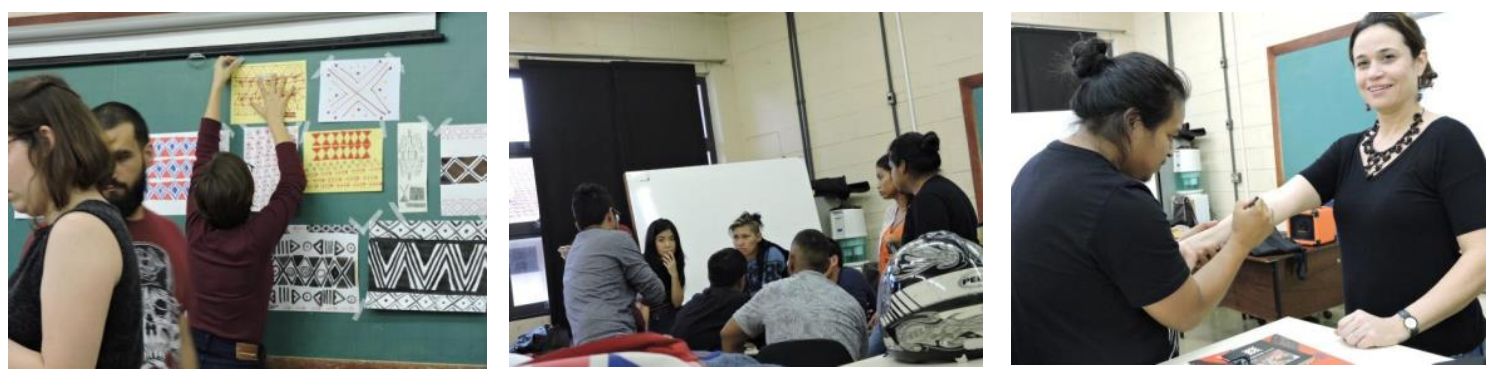

Figura 1: Oficina de Grafismos Indígenas 2017 (primeiro dia)

Fonte: Leticia Albanez

A dinâmica da oficina, ainda que pré estruturada, ocorreu de maneira informal; o que possibilitou uma relação de igual para igual entre os agentes sociais participantes (CAVALCANTE et al., 2018, p. 1407).

O segundo dia da oficina foi dedicado à aplicação dos grafismos desenhados no dia anterior em produtos têxteis, como lenços e estojos, pela técnica da impressão pela sublimação (Figura 2). Nesse aspecto da oficina fica evidente a colaboração e a troca de conhecimento entre os designers e os estudantes indígenas, um processo que resultou em produtos de design como sugestões de recursos para as comunidades indígenas se apropriarem em benefício de suas condições materiais e visibilidade cultural.

Compreende-se o acontecimento desta oficina, com seus diversos agentes envolvidos, um momento de sobreposições de práticas, em que dois agentes sociais carregados de história, identidade e uma prática definida, se uniram em uma instituição para trocar conhecimentos, histórias e experiências em torno de uma prática. Esse cenário pode ser lido como um pontapé para a formação de outra comunidade de prática, mista, entre os estudantes indígenas da Universidade e os demais estudantes de outras identidades sociais: professores, servidores e alunos de diversas áreas do conhecimento.

A oficina referida tem todos os aspectos descritos por Wenger no que se trata do encontro de práticas (1998, p. 114), porque nela aconteceram negociação de iniciativas, negociação de sentidos e perspectivas distintos, com a presença de mecanismos comunicativos desses significados e práticas e a produção de artefatos culturais que envolvem o desenho do grafismo indígena e a impressão desses desenhos em técnicas ocidentais. Além disso, a maneira como a criação dos produtos de design gerados operou foge da maneira como o mercado tradicionalmente opera, constituindo uma ruptura nos padrões de comportamento sociais e de produção.
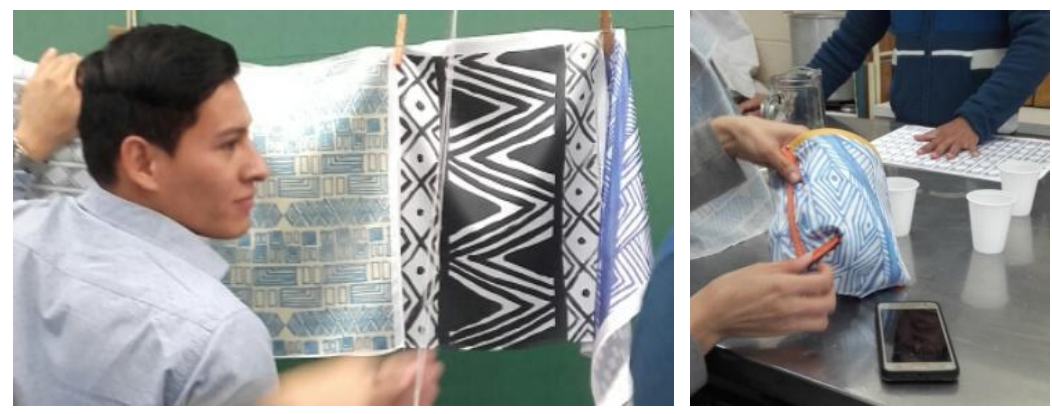

Figura 2: Artefatos finais da oficina de Grafismos Indígenas

Fonte: Elaborado pelas autoras, 2017 
Situação semelhante a essa oficina veio a acontecer em agosto de 2019, envolvendo estudantes indígenas e participantes de um grupo de pesquisas indígenas coordenado pelo professor Wagner R. Amaral, que envolve estudantes de Design, Serviço Social, Ciências Sociais e Comunicação, desde a graduação até a pós-graduação (Figura 3).

A oficina é parte de um projeto que visa a criação de um livro sobre memórias indígenas, e ela é um espaço para possibilitar a criação coletiva interdisciplinar deste artefato. Foi ensinada a técnica da xilogravura (gravura em madeira) para os indígenas da região oeste de Londrina em uma oficina anterior, pela professora de gravura Maria Fiorato; e estas foram impressas no dia 02 de agosto, na sala do CICLO Intercultural da UEL, que é a sala em que os estudantes indígenas passam por um período de integração antes de ingressar aos cursos de graduação da Universidade. A parte da impressão foi realizada com a presença de dois indígenas e cerca de dez não-indígenas, participantes do grupo de pesquisas indígenas no qual a oficina foi divulgada.

A pesquisadora em questão teve o seu primeiro contato com o grupo de pesquisa nesta oficina específica, e perguntou para a professora Maria o contexto em que ela estava sendo realizada. Segundo ela, foi impressionante dar aulas de gravura aos indígenas, pois eles possuem uma habilidade incrível de escultura; a arte para a comunidade Guarani não é uma prática separada da vida, como é para nós. Os resultados dos desenhos são maravilhosos, pois eles tiveram mesmo no primeiro contato com o processo de gravação da matriz de madeira uma facilidade para trabalhar com desenhos figurativos, complexos e carregados de textura. Esse aspecto é muito relevante para esta pesquisa, pois indica que ocorreu uma troca de conhecimentos tácitos visuais entre os indígenas e os não-indígenas no momento daquela oficina.

A prática da impressão da gravura foi realizada de maneira informal, semiestruturada: os participantes que chegavam primeiro ajudavam no que podiam, a professora dava instruções e era aberta a sugestões dos alunos. Algumas vezes as instruções sobre a impressão eram passadas de forma multidirecional, de aluno para aluno. Ao longo do tempo, conversas informais foram se desdobrando sobre a Universidade e outros temas aleatórios, criando uma unificação das pessoas participantes que antes não se conheciam, e formando o começo de uma identidade coletiva.

Ao longo da prática, a professora indicava tarefas a cada participante que correspondiam a cada etapa do processo de impressão: a professora preparava a tinta e passava na matriz, outro participante com a mão limpa separava o papel, outro carregava o papel e a matriz juntos à prensa, outro prensava, e outro pendurava num varal da sala para secar. Nenhuma dessas seleções foi feita de maneira impositiva ou com discordâncias, sendo uma interação leve dos participantes com a prática, o que demonstra que todos ali estavam dispostos a aprender.

Outro acontecimento importante da oficina, além da realização das impressões, foi a decisão do formato do livro e o tipo de papel. O professor Wagner levou exemplares para serem consultados e experienciados por todos os participantes, buscando referências para basear a decisão.

Os resultados de produtos da oficina incluem as impressões brutas, que podem ser expostas, e as impressões que farão parte do livro de Memórias Indígenas; e o próprio livro em si, que será desenvolvido em outros momentos do projeto. 
Esta oficina apresenta-se como outro caso de construção colaborativa do processo de produção de um artefato, que foge dos padrões da indústria contemporânea, estabelecendo relações de igual para igual com todos os agentes sociais - estudantes indígenas e não-indígenas, e professores envolvidos. Apesar de ter tal artefato gráfico em mente, os participantes fizeram algumas sugestões para aplicação: almofadas, cópias para impressões, camisetas; de forma espontânea, demonstrando interesse genuíno pelo objeto de aprendizado e prática.
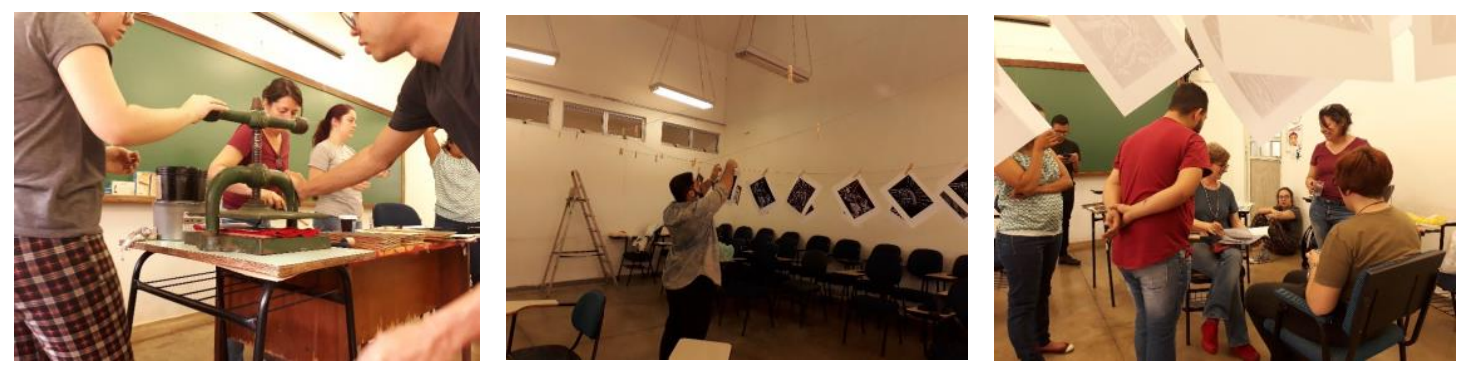

Figura 3: Artefatos finais da oficina de Grafismos Indígenas

Fonte: Elaborado pelas autoras, 2019

\section{Comparação e análise}

Os relatos realizados sobre o funcionamento das duas oficinas, descritos neste trabalho, foram organizados em um mapa mental (Figura 4) e suas características foram comparadas com conceitos teóricos dos autores Wenger (1998) e Manzini (2008). As informações do mapa mental estão categorizadas por cores: amarelo para características das práticas realizadas; laranja para características dos grupos envolvidos e a dinâmica da oficina; azul turquesa para os conceitos de Wenger (1998), e verde claro para os conceitos de Manzini (2008).

A primeira característica de ambas as oficinas são os seus participantes, que se configuram como agentes sociais distintos, carregados de sua identidade sociocultural de brasileiros nãoindígenas e brasileiros indígenas. Entende-se que a intersecção de duas comunidades diferentes, de identidades distintas, configura uma esfera em que há articulação de duas comunidades próximas a nível local, formando uma constelação de práticas e sentidos. Não é possível afirmar que as duas comunidades são Comunidades de Prática, mas é possível reconhecer as quatro características principais das CoPs em cada uma: prática, identidade, sentido e comunidade. As duas comunidades juntas formam uma identidade mais geral, que é de estudantes em uma Universidade do Brasil.

As iniciativas de oficinas que estamos observando não são a nível global: são iniciativas locais, que ocorrem na direção de baixo para cima, encontrando o requisito de Manzini para os empreendimentos promissores (2008, p. 75).

As comunidades, quando unidas, estavam ativamente engajadas com a mesma prática, que é um resultado da sobreposição de duas práticas características de cada comunidade: o desenho do grafismo indígena e as técnicas de impressão ocidentais (a xilogravura e a sublimação), correspondendo ao conceito de Encontro de Práticas de Wenger (1998, p. 114). Essa troca de conhecimentos pode ser lida como uma negociação de sentidos e significados, pois cada prática 
tem um significado historicamente construído para cada comunidade e esses significados foram trocados, inseridos em outros contextos e reinterpretados.

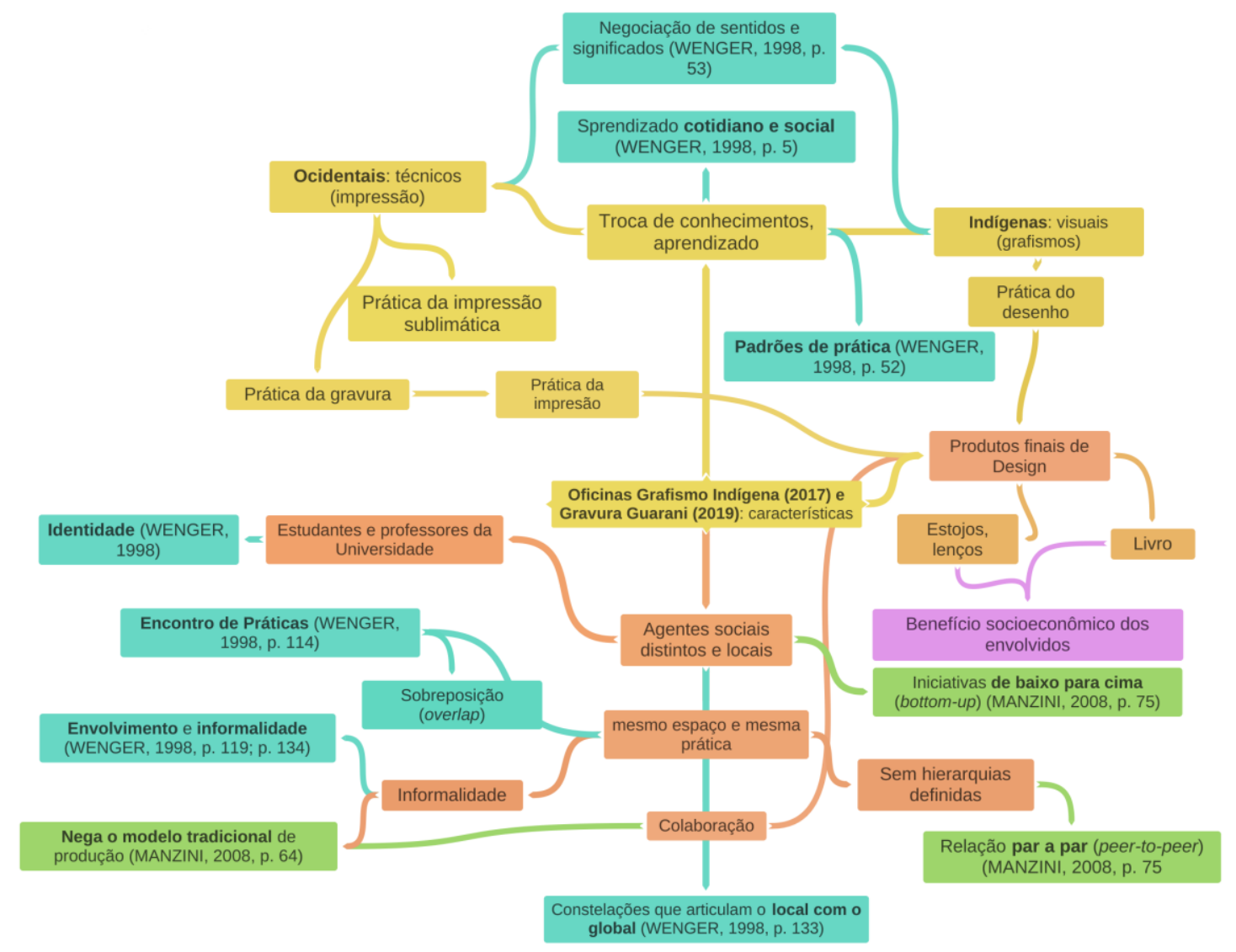

Figura 4: Mapa mental sobre as oficinas estudadas. Fonte: Elaborado pelas autoras, 2019

Esse processo de negociação de significados e sentidos aconteceu de maneira informal e colaborativa, negando assim os modelos tradicionais de produção industriais. Em ambas as oficinas, não havia hierarquia clara entre os participantes de ambas as comunidades, o que demonstra uma relação par-a-par tratada por Manzini (2008, p.75).

Além do aprendizado cotidiano e social que cada participante das oficinas experienciou, elas resultaram em produtos de design que são artefatos culturais: a oficina de 2017 gerou lenços e estojos ornados por grafismos Guarani e Kaingang, e a oficina de 2019 gerou um livro que registra a memória Indígena Guarani. Estabelecendo uma relação com o princípio de Inovação Social e das Comunidades Criativas de Manzini, as oficinas serviram para que as comunidades encontrassem soluções criativas para lidar com seus problemas cotidianos: a comunidade indígena pode se utilizar dos artefatos para venda e distribuição, fomentando sua economia, e a presença dos grafismos e de seus significados culturais nos artefatos é compreendida como fator de valorização cultural e visibilidade para a comunidade indígena dentro e fora da Universidade. Já os estudantes e professores não-indígenas tiveram o benefício do conhecimento e atividades dentro da Universidade, bem como a realização de suas pesquisas. 


\section{Considerações finais}

O contexto contemporâneo da emergência da sociedade baseada no conhecimento exige que novas formas de fazer design sejam exploradas e trabalhadas, correspondendo ao que Manzini (2008) chama de Inovação social dos modos de vida, produção e consumo. Novos modos de produção e de pensamento de design que desviam dos padrões industriais e do mercado devem ser cada vez mais incentivados, resultando em comunidades criativas de alto potencial de transformação social rumo à sustentabilidade a nível sistêmico e estrutural.

Foram tratados os conceitos de Comunidades Criativas (MANZINI, 2008) e Comunidades de Prática (WENGER, 1998) como soluções estruturais na sociedade para causar descontinuidades sistêmicas e gerar inovação social e sustentabilidade. Duas oficinas realizadas na Universidade Estadual de Londrina por professores e estudantes indígenas e não-indígenas foram descritas e interpretadas a partir desses dois tratamentos teóricos.

Conclui-se que os casos estudados nesse trabalho são Comunidades de Prática em estado potencial (WENGER, 1998, p. 228) e casos promissores de comunidades criativas (MANZINI, 2008 , p. 75) porque lidam com seus interesses e buscam soluções para seus problemas cotidianos de maneira informal dinâmica, democrática e semiestruturada, além de ter a capacidade de formar relações par-a-par com outras comunidades criativas por meio da prática do design.

Esta pesquisa gera alguns desdobramentos de ordem interpretativa, que envolvem as seguintes questões: Qual o sistema habilitante envolvido com a formação das duas comunidades criativas de prática, considerando que toda a infraestrutura das oficinas é proveniente da Universidade? Seria possível um cenário de solução habilitante que não dependesse do fomento do Governo do Estado e do Governo Federal para que novas comunidades criativas de prática possam surgir em contextos fora da Universidade?

Este trabalho é mais uma tentativa de alimentar o paradigma científico contemporâneo do Design para a Sustentabilidade Social. Chama-se a atenção para a necessidade de produções teóricas na área do Design de caráter crítico sobre a prática atual do designer e sobre seus impactos sociais de forma estrutural e sistêmica.

\section{Referências}

CARDOSO, Rafael. Design para um mundo complexo. São Paulo: Ubu, 2016. 264p.

CAVALCANTE, Ana Luisa Boavista Lustosa. Design para a sustentabilidade cultural: recursos estruturantes para sistema habilitante de revitalização de conhecimento local e indígena. 2014. 321 f. Tese (Doutorado) - Curso de Engenharia e Gestão do Conhecimento, Centro Tecnológico, Universidade Federal de Santa Catarina, Florianópolis, 2014. Disponível em: https://repositorio.ufsc.br/handle/123456789/132600. Acesso em: 05 nov. 2018.

CAVALCANTE, Ana Luisa et al. Design Colaborativo e Visibilidade Indígena na Universidade: uma ação para a sustentabilidade da diversidade cultural.. In: ENCONTRO DE SUSTENTABILIDADE EM PROJETO, 5., 2018, Florianópolis. Anais... . Florianópolis: Ufsc/virtuhab, 2018. p. 1402 - 1414. Disponível em: http://ensus2018.paginas.ufsc.br/anais/. Acesso em: 10 jun. 2019. 
BONSIEPE, Gui. Sobre Design e Política. In: Do material ao Imaterial. São Paulo: Blucher, 2015, p. 193-198.

BONSIEPE, Gui. Design, cultura e sociedade. São Paulo: Blucher, 2011. 270p.

BUCHANAN, Richard. Wicked problems in design thinking. Design issues, v. 8, n. 2, p. 5$21,1992$.

MANZINI, Enzio. Design para a inovação social e sustentabilidade: comunidades criativas, organizações colaborativas e novas redes projetuais. Rio de Janeiro: E-papers, 2008. 104p.

MANZINI, Ezio. Metaprojeto hoje: guia para uma fase de transição. In: MORAES, Dijon De. Metaprojeto: o design do design. São Paulo: Blucher, 2010. p. IX-XIII.

MARTTILA, Tatu. Platforms of co-creation: Learning Interprofessional Design Practice in Creative Sustainability. 2018. 280 f. Tese (Doutorado) - Curso de Creative Sustainability, Department Of Design, Aalto University School Of Arts, Design And Architecture, Helsinki, 2018. Disponível em:

https://www.researchgate.net/publication/332112307_PLATFORMS_OF_COCREATION_Learning_Interprofessional_Design_Practice_in_Creative_Sustainability. Acesso em: 01 ago. 2019.

MARGOLIN, Victor; MARGOLIN, Sylvia. A "Social Model” of Design: Issues of Practice and Research. Design Issues, [s.1.], v. 18, n. 4, p.24-30, out. 2002. MIT Press - Journals. http://dx.doi.org/10.1162/074793602320827406.

MINAYO, Maria Cecília de Souza (Org.). Et al. Pesquisa social: Teoria, método e criatividade. Petrópolis, RJ: Vozes, 1994.

REY, Ferdinando González. Pesquisa Qualitativa e Subjetividade: os processos de construção da informação. Tradução por Marcel Aeistides Ferrada Silva - São Paulo: Cengage Learning, 2015.

SAMPAIO, Cláudio Pereira de. FLOWS: Modelo integrado de P\&D em resíduos sólidos. Orientadores: Suzana Barreto Martins, Fernando José Carneiro Moreira da Silva, Rita Assoreira Almendra. 2017. 240 f. Tese (Doutorado em Design) - Faculdade de Arquitetura, Universidade de Lisboa, Lisboa, 2017.

URIARTE, Urpi Montoya. O que é fazer etnografia para os antropólogos. Ponto Urbe. Revista do núcleo de antropologia urbana da USP, n. 11, 2012.

\section{Sobre as autoras}

\section{Ana Luisa Boavista Lustosa Cavalcante}

Docente no Curso de Graduação em Design Gráfico e nos cursos de Pós-graduação em Design da Universidade Estadual de Londrina. Doutora em Engenharia e Gestão do Conhecimento (UFCS). Mestre em Engenharia de Produção pela Universidade Federal do Rio de Janeiro. Atua nas áreas: design gráfico; cultura visual e design e sustentabilidade cultural. Líder do Grupo de Pesquisa: Design para a Sustentabilidade e Inovação Social/UEL/CNPq.

https://orcid.org/0000-0002-0852-1746.

\section{Natalia Maria Devergenes}

Graduanda em Design Gráfico da Universidade Estadual de Londrina. Atua nas áreas: Teoria e História do Design; Linguagem visual; e Design para a sustentabilidade cultural. https://orcid.org/0000-0002-0754-9798. 